\title{
Amelioration of Albuminuria in Japanese Type 2 Diabetic Patients by Maximal Dose of Candesartan
}

\author{
Yoichi Oikawa $^{1,2}$, Akira Shimada ${ }^{1}$, Mizumi Kyo ${ }^{2}$ \\ ${ }^{1}$ Department of Internal Medicine, Tokyo Saiseikai Central Hospital, Tokyo, Japan \\ ${ }^{2}$ Department of Internal Medicine, Eiju General Hospital, Tokyo, Japan \\ Email: oikawa@saichu.jp
}

Received August 12, 2013; revised August 31, 2013; accepted September 10, 2013

Copyright (C) 2013 Yoichi Oikawa et al. This is an open access article distributed under the Creative Commons Attribution License, which permits unrestricted use, distribution, and reproduction in any medium, provided the original work is properly cited.

\begin{abstract}
Introduction: It was recently reported that candesartan, an angiotensin II receptor blocker, had a protective effect against cardiovascular events, comparable to that of calcium channel antagonists. Moreover, a renoprotective effect and anti-diabetic action of candesartan had also been demonstrated. However, whether the renoprotective effect of candesartan, especially in diabetes, was dose-dependent or not remain to be fully elucidated. The present study attempted to clarify the dose effect of renoprotection by candesartan in Japanese type 2 diabetic patients. Subjects and Method: In this case series study, we recruited 26 type 2 diabetic patients with albuminuria whose blood pressure did not reach the target BP level $(<130 / 80 \mathrm{mmHg})$ despite administration of 4 or $8 \mathrm{mg}$ /day of candesartan. Subsequently, these lower doses of candesartan were increased to the maximal dose in Japan, $12 \mathrm{mg} /$ day. Clinical parameters were examined before, at 6 and 12 months after the increase in dose. Results: An ameliorating effect of the increased dose of candesartan on albuminuria and hypertension was distinctly observed. No severe adverse effect was observed. Conclusion: It was highly possible that the maximal dose of candesartan provided more effective renoprotection in hypertensive type 2 diabetic patients initially treated with lower doses of candesartan.
\end{abstract}

Keywords: Albuminuria; Angiotensin II Receptor Blocker (ARB); Candesartan; Hypertension; Type 2 Diabetes

\section{Introduction}

Diabetes is a chronic disease that occurs either when the pancreas does not produce enough insulin or when the body cannot effectively use the insulin it produces. Diabetes without proper treatment can cause many complications, such as diabetic retinopathy, nephropathy and neuropathy. Diabetes, as well as hypertension, dyslipidemia and obesity, is believed to be a strong risk factor for cardiovascular disease [1]. Especially, the existence of albuminuria, a characteristic of diabetic early nephropathy, is considered to be an important risk factor for increased cardiovascular events in diabetic patients [2].

Recently, the number of new cases of dialysis due to diabetic nephropathy has been increasing in a linear fashion in Japan [3], implying that prevention of the development of diabetic nephropathy is absolutely imperative. It is generally considered that the prevention of diabetic nephropathy requires strict blood pressure (BP) control as well as good control of the blood glucose level

*Disclosure Statement: The Authors declare that there is no conflict of interest. and an appropriate protein-restricted diet. At present, the Japanese Society of Hypertension Guidelines for the Management of Hypertension (JSH 2009) recommend that the target systolic and diastolic BP in diabetic patients are set at $<130 \mathrm{mmHg}$ and $<80 \mathrm{mmHg}$, respectively [4], and $<125 \mathrm{mmHg}$ and $<75 \mathrm{mmHg}$ in patients with more than $1 \mathrm{~g}$ /day of proteinuria, respectively. However, the rate of achievement of the target BP seems to be low and is not be satisfactory in clinical settings.

The renin-angiotensin system (RAS) plays a critical role in the pathogenesis of chronic kidney disease (CKD) as well as hypertension and cardiovascular events [5], and inhibition of RAS by angiotensin II receptor blockers (ARB) is known to confer a protective action not only on renal function, but also on cardiovascular organs in diabetic [6] as well as non-diabetic [7] hypertensive patients with CKD. On the other hand, it is unknown whether the renoprotective effect of ARBs, especially in diabetics, is dose-dependent or not. Regarding this point, the incipient to overt, angiotensin II blocker, telmisartan, investigation on type 2 diabetic nephropathy (INNOVATION) 
study demonstrated a higher remission rate of microalbuminuria in Japanese type 2 diabetic patients with albuminuria administered telmisartan as compared to placebo [8]. However, when the telmisartan-treated subjects were divided into high-dose and low-dose groups, no significant difference in the remission rate of microalbuminuria was observed between the two.

The Candesartan Antihypertensive Survival Evaluation in Japan (CASE-J) trial recently revealed a protecttive effect of candesartan against cardiovascular events comparable to that of amlodipine and an anti-diabetic effect [9]. In addition, sub-analysis of the CASE-J trial also showed a renoprotective effect of candesartan in hypertensive patients with CKD [10]. However, the dose effect of renoprotection by candesartan in diabetics remains to be elucidated. To investigate whether the renoprotective effect of candesartan in diabetes is dose-dependent or not, we increased the prescribed amount of candesartan from lower doses to the maximal dose in Japanese type 2 diabetic patients with hypertension and albuminuria, and evaluated the time course of a variety of clinical parameters including urine albumin excretion (UAE) level.

\section{Subjects and Method}

\subsection{Study Design}

This study was an uncontrolled longitudinal observational study; i.e. a case series study.

Fifty-six Japanese type 2 diabetic patients with hypertension, whose BP did not reach the target systolic/diastolic BP $(<130 / 80 \mathrm{mmHg})$ despite administration of 4 or $8 \mathrm{mg}$ /day of candesartan for more than 6 months, were recruited at Eiju General Hospital. Of these patients, 26 were shown to have albuminuria without overt proteinuria, and their baseline UAE level in a single spot-urine collection ranged from 31.2 to $620.0 \mathrm{mg} / \mathrm{gCr}$ (creatinine). After the need for an increase in dose to reach the target BP level was approved by the 26 patients, the dose of candesartan ( $4 \mathrm{mg} /$ day or $8 \mathrm{mg}$ /day) was increased to the maximal dose in Japan, i.e. $12 \mathrm{mg} /$ day. Venous blood samples were obtained from the patients regardless of fasting or non-fasting state and a variety of clinical parameters were investigated before, at 6 months and 12 months after the increase in dose. Exclusion criteria were as follows; type 1 diabetes, patients with stage I (UAE level $<30 \mathrm{mg} / \mathrm{gCr}$ ), IIIb (urine protein level $\geq 1 \mathrm{~g} /$ day or estimated glomerular filtration rate (eGFR) $<60 \mathrm{~mL} /$ $\min / 1.73 \mathrm{~m}^{2}$ ), IV (increased serum creatinine level above normal range) or $\mathrm{V}$ (receiving dialysis) diabetic nephropathy, serum potassium level $>5.5 \mathrm{mEq} / \mathrm{L}$, unconsenting patients, overt bacteriuria, severe autonomic neuropathy including orthostatic hypotension, seated systolic $\mathrm{BP} /$ diastolic $\mathrm{BP} \geq 180 / 100 \mathrm{mmHg}$, severe liver dysfunc- tion and definable chronic kidney disease other than diabetic nephropathy.

Hemoglobin A1c (HbA1c) was expressed as a NGSP (National Glycohemoglobin Standardization Program) equivalent value in this study; i.e., HbA1c (NGSP equivalent value) $(\%)=$ HbA1c (Japan Diabetes Society value) $(\%)+0.4 \%$.

\subsection{Statistical Analysis}

Data are expressed as mean \pm S.D. Continuous variables were compared using paired $t$-test. A $P$ value less than 0.05 was considered to be statistically significant.

\section{Results}

\subsection{Patients’ Baseline Characteristics}

The mean age of the 26 patients ( 21 male, 5 female) with albuminuria was 60.3 years, their mean BMI was 25.9 $\mathrm{kg} / \mathrm{m}^{2}$ and their mean systolic/diastolic BP was $145.3 /$ $85.6 \mathrm{mmHg}$ at enrollment (Table 1). Of the 26 patients, $4 \mathrm{mg} /$ day and $8 \mathrm{mg} /$ day of candesartan had been initially prescribed to 15 patients and 11 patients, respectively. $\mathrm{Ca}$ channel antagonists were administered in 57.7\% (15/26) of the patients, whereas one patient was treated with an $\alpha$-blocker and no patient was treated with a $\beta$-blocker or diuretic. Approximately $70 \%(18 / 26)$ of patients were treated with a sulfonylurea, 46.2\% (12/26) with an $\alpha$ glucosidase inhibitor, $38.5 \%(10 / 26)$ with a biguanide, and $26.9 \%(7 / 26)$ with a thiazolidine against type 2 diabetes. Insulin treatment was given in $15.4 \%(4 / 26)$ of patients. During this study, the dose of sulfonylurea was increased in one patient, and the dose of thiazolidine was increased in another one. However, there was no change in the formulation of any drugs other than candesartan or that of insulin therapy during the observation period.

\subsection{UAE Level Was Improved by Increase in Candesartan to Maximal Dose}

UAE level was investigated before (at baseline), at 6 months and 12 months after an increase in dose of candesartan from 4 or $8 \mathrm{mg}$ /day to $12 \mathrm{mg} /$ day. As shown in Table 1 and Figure 1, UAE level slightly decreased between baseline and 6 months, but there was no significant difference in UAE level between the two time points. Ultimately, UAE level was significantly decreased at 12 months as compared to baseline and 6 months.

\subsection{BP Was Significantly Decreased by Increase in Candesartan to Maximal Dose}

The increase in dose of candesartan to $12 \mathrm{mg}$ /day resulted in significant decreases in systolic and diastolic BP both at 6 and 12 months as compared to the baseline systolic and diastolic BP, though there was no significant 
Table 1. Patients' clinical characteristics.

\begin{tabular}{|c|c|c|c|}
\hline & Baseline (0 M) & 6 months $(6 \mathrm{M})$ & 12 months $(12 \mathrm{M})$ \\
\hline Number & 26 & - & - \\
\hline Sex (male/female) & $21 / 5$ & - & - \\
\hline Age (years) & $60.3 \pm 11.5$ & - & - \\
\hline Duration of diabetes (years) & $8.9 \pm 3.9$ & - & - \\
\hline Initial dose of candesartan before increase to $12 \mathrm{mg} / \mathrm{day}(4 \mathrm{mg} / 8 \mathrm{mg})$ & $15 / 11$ & - & - \\
\hline Current smoking (yes/no) & $13 / 13$ & - & - \\
\hline \multicolumn{4}{|l|}{ Medications } \\
\hline $\mathrm{Ca}$ antagonist (yes/no) & $15 / 11$ & - & - \\
\hline$\alpha$-blocker (yes/no) & $1 / 25$ & - & - \\
\hline Sulfonylurea (yes/no) & $18 / 8$ & - & - \\
\hline Glinide (yes/no) & $1 / 25$ & - & - \\
\hline Biguanide (yes/no) & $10 / 16$ & - & - \\
\hline Thiazolidine (yes/no) & $7 / 19$ & - & - \\
\hline$\alpha$-glucosidase inhibitor (yes/no) & $12 / 14$ & - & - \\
\hline Insulin therapy (yes/no) & $4 / 22$ & - & - \\
\hline Statin (yes/no) & $7 / 19$ & - & - \\
\hline Fibrate (yes/no) & $3 / 23$ & - & - \\
\hline \multicolumn{4}{|l|}{ Clinical parameters } \\
\hline Body mass index $\left(\mathrm{kg} / \mathrm{m}^{2}\right)$ & $25.9 \pm 4.4$ & $25.7 \pm 4.3$ & $25.8 \pm 4.3$ \\
\hline Systolic BP (mmHg) & $145.3 \pm 8.7$ & $134.4 \pm 12.3^{*}$ & $137.3 \pm 9.5^{*}$ \\
\hline Diastolic BP (mmHg) & $85.6 \pm 7.9$ & $78.4 \pm 8.3^{*}$ & $80.0 \pm 6.6^{*}$ \\
\hline Serum $\mathrm{Cr}(\mathrm{mg} / \mathrm{dl})$ & $0.86 \pm 0.29$ & $0.83 \pm 0.27$ & $0.88 \pm 0.27^{\# \#}$ \\
\hline HbA1c (NGSP) (\%) & $7.52 \pm 0.96$ & $7.51 \pm 0.97$ & $7.36 \pm 0.96$ \\
\hline Serum potassium $(\mathrm{mEq} / \mathrm{L})$ & $4.24 \pm 0.41$ & $4.37 \pm 0.32^{* *}$ & $4.34 \pm 0.40$ \\
\hline Total cholesterol (mg/dL) & $197.9 \pm 33.7$ & $196.5 \pm 39.5$ & $193.7 \pm 33.8$ \\
\hline HDL-C (mg/dL) & $56.8 \pm 14.5$ & $55.3 \pm 15.0$ & $55.0 \pm 14.5$ \\
\hline Triglyceride (mg/dL) & $168.5 \pm 90.8$ & $164.5 \pm 98.2$ & $146.8 \pm 74.3$ \\
\hline Non-HDL-C (mg/dL) & $141.1 \pm 37.1$ & $141.2 \pm 40.4$ & $138.6 \pm 34.2$ \\
\hline $\mathrm{UAE}(\mathrm{mg} / \mathrm{gCr})$ & $147.8 \pm 155.0$ & $124.5 \pm 155.3$ & $91.9 \pm 100.3^{* \#}$ \\
\hline
\end{tabular}

${ }^{*} ; P<0.01$ vs. $0 \mathrm{M}$ by paired $t$-test, ${ }^{* *} ; P<0.05$ vs. $0 \mathrm{M}$ by paired $t$-test, ${ }^{\#} ; P<0.05$ vs. $6 \mathrm{M}$ by paired $t$-test, ${ }^{\# \#}: P<0.01$ vs. $6 \mathrm{M}$ by paired $t$-test. BP: blood pressure, Ca: calcium, Cr: creatinine, HDL-C: high-density lipoprotein-cholesterol, NGSP: National Glycohemoglobin Standardization Program, UAE: urine albumin excretion.

difference in both systolic and diastolic BP between 6 and 12 months (Table 1 and Figures 2(a) and (b)).

\subsection{Maximal Dose of Candesartan Did Not Affect HbA1c Level}

The CASE-J trial revealed that candesartan has the capa- bility to protect against new onset of type 2 diabetes [9], suggesting an anti-diabetic effect of candesartan. To clarify the effect of candesartan on glucose tolerance, we investigated the time course of $\mathrm{HbA} 1 \mathrm{c}$ level. As shown in Table 1 and Figure 3, HbA1c level tended to decrease with time, although there was no significant difference in 


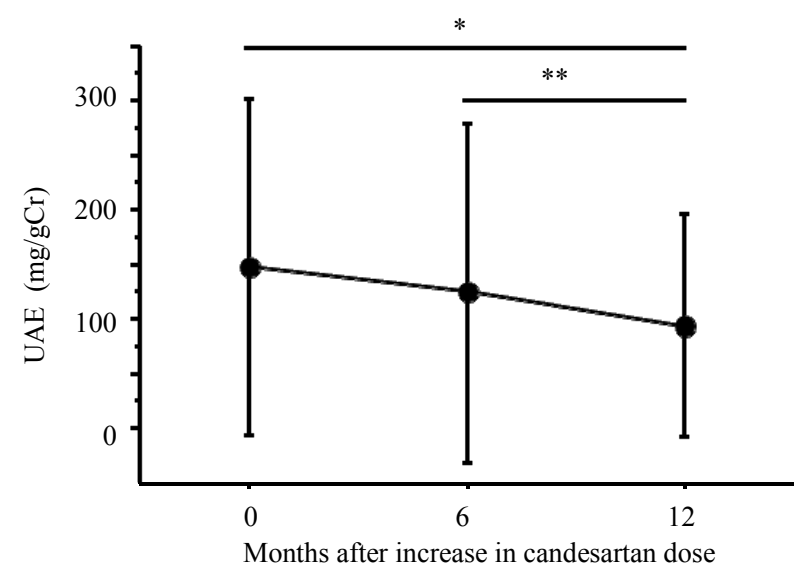

Figure 1. Time course of UAE level by $12 \mathrm{mg} /$ day of candesartan. Changes in UAE level of the patients are shown $(\mathrm{n}=26)$. ${ }^{*} ; \boldsymbol{P}<0.01$ and ${ }^{* *} ; \boldsymbol{P}<0.05$ by paired $\boldsymbol{t}$-test. $\mathrm{Re}-$ sults are mean \pm S.D. UAE: urine albumin excretion.

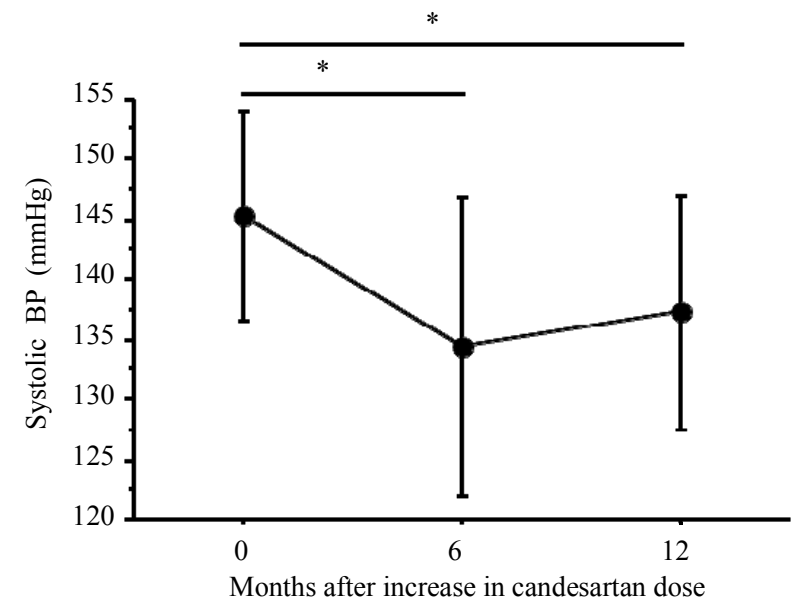

(a)

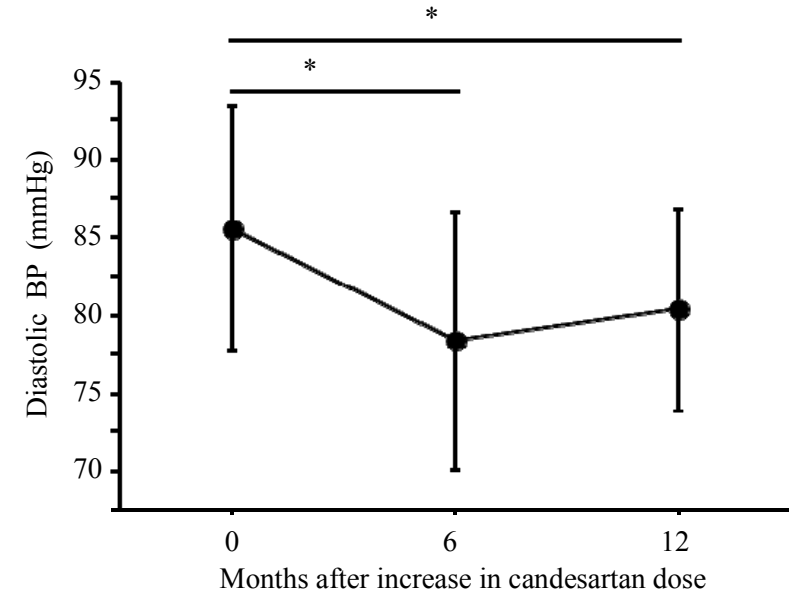

(b)

Figure 2. Time course of blood pressure by $12 \mathrm{mg} /$ day of candesartan. (a, b) Changes in systolic (a) and diastolic (b) blood pressure of the patients are shown $(n=26)$. *; $P<$ 0.05 by paired $t$-test. Results are mean \pm S.D. BP: blood pressure.

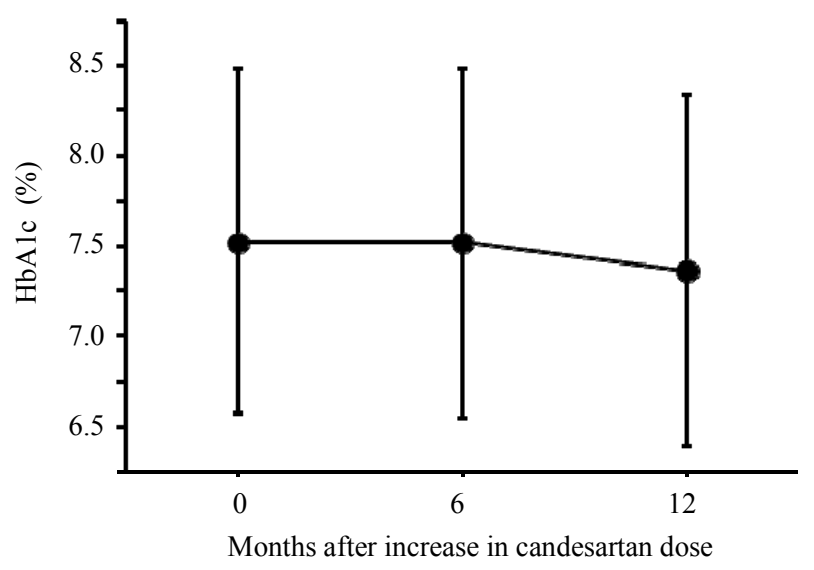

Figure 3. Time course of HbA1c level by $12 \mathrm{mg} /$ day of candesartan. Changes in HbA1c level of the patients are shown $(n=26)$. No significant difference in HbA1c level among each time point was observed. Results are mean \pm S.D.

HbA1c level among each time point. Similarly, body mass index and lipid profile were not affected by the increase in dose of candesartan (Table 1).

\subsection{Adverse Effects of Maximal Dose of Candesartan}

With regard to adverse effects of the increase in dose of candesartan, we measured serum $\mathrm{Cr}$ level and serum potassium level. As a result, serum $\mathrm{Cr}$ level was increased from 6 to 12 months, although its change seemed to be clinically negligible (Table 1 and Figure 4(a)). On the other hand, serum potassium level was slightly increased at 6 months, and thereafter was restored to near the baseline level at 12 months (Table 1 and Figure 4(b)). No other adverse effect attributable to the increase in dose of candesartan was observed.

\section{Discussion}

The present study demonstrated an ameliorating effect of an increase in dose of candesartan from 4 or $8 \mathrm{mg}$ /day to $12 \mathrm{mg} /$ day on UAE level, suggesting that the maximal dose of candesartan probably provides more effective renoprotection in Japanese type 2 diabetic patients with hypertension initially treated with lower doses of candesartan.

Growing evidence has suggested that RAS inhibitors have protective effects against the development of proteinuria and the loss of renal function, the mechanisms for which are believed to be partially independent of the BP-lowering effect [11]. In the present study, the maximal dose of candesartan provided a significant improvement in both BP and UAE level at 12 months, indicating a close correlation between BP lowering and renoprotection (Figures 1, 2(a) and (b)). On the other hand, considering that UAE level significantly decreased between 


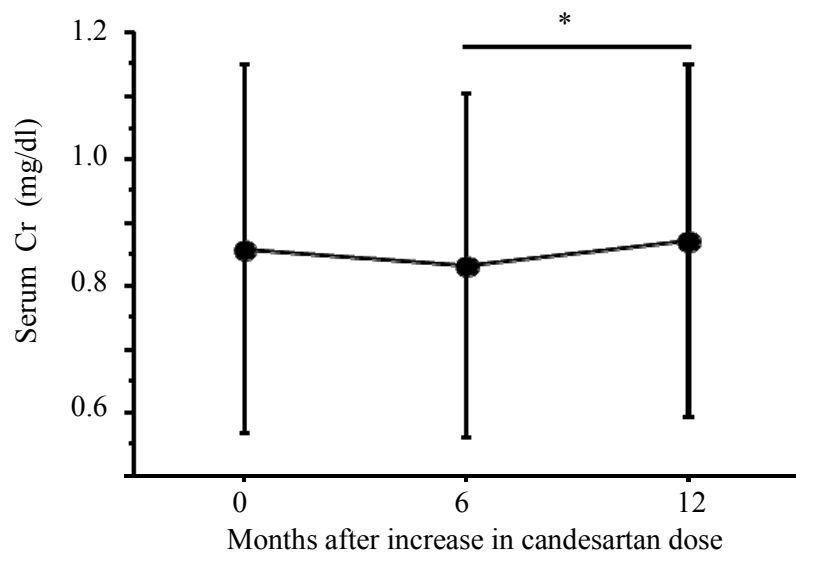

(a)

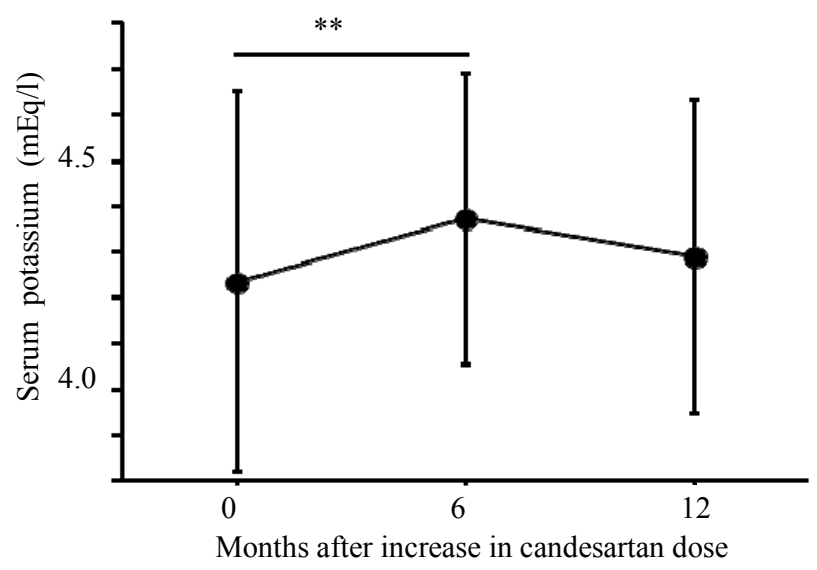

(b)

Figure 4. Time courses of serum $\mathrm{Cr}$ and potassium levels by $12 \mathrm{mg} /$ day of candesartan. (a, b) Changes in serum $\mathrm{Cr}$ level (a) and serum potassium level (b) of the patients are shown $(\mathrm{n}=26) .{ }^{*} ; \boldsymbol{P}<0.01$ and ${ }^{* *} ; \boldsymbol{P}<0.05$ by paired $\boldsymbol{t}$-test. Results are mean \pm S.D. Cr: creatinine.

6 and 12 months despite a slight increase in mean BP over the same period, the renoprotective action of candesartan may be partially provided by a class effect of ARBs beyond their BP-lowering effect. The INNOVATION study demonstrated a significant reduction in albuminuria in type 2 diabetes by both high and low doses of telmisartan [8]. Although the renoprotective effect of a high dose of telmisartan tended to be superior to that of a low dose of telmisartan, no significant difference in the effect was actually observed between the two doses; these findings seem to conflict with our findings. Intriguingly, the degree of BP lowering in the high-dose telmisartan group was comparable to that in the low-dose group in the INNOVATION study at the final observation, whereas in our study, a significant decrease in BP by an increase in the dose of candesartan was observed at the final observation. Therefore, the difference in BPlowering effect of the two ARBs might have contributed to the discrepancy in dose effect of the two ARBs on re- noprotection between their and our reports, although further investigation is required.

As for the association between the dose of candesartan and renoprotection, Rossing et al. previously demonstrated that the renoprotective effect of candesartan was exerted in dose-dependent manner in type 2 diabetic patients with nephropathy [12]. In their study, the patients were randomly assigned to receive candesartan at a dose of 8,16 or $32 \mathrm{mg} /$ day. However, the doses of $16 \mathrm{mg} /$ day and $32 \mathrm{mg} /$ day are beyond the recommended dose range of candesartan applied in Japan. Moreover, the treatment using each dose of candesartan was provided for only 2 months; i.e. a long-term renoprotective effect of candesartan remained to be elucidated. Therefore, it would appear that their findings can not be applied to the clinical situation in Japan.

Microalbuminuria is considered to be a risk factor for cardiovascular disease [2], and the amelioration of UAE level by intervention with ARBs was reported to contribute to the risk reduction of future cardiovascular events in clinical studies. For example, the Reduction in Endpoints in Non-insulin dependent diabetes mellitus with the angiotensin II Antagonist Losartan (RENAAL) study showed that a decrease in albuminuria by losartan led to a significant reduction in cardiovascular and heart failure risks [13]. Similarly, the Losartan Intervention For Endpoint reduction in hypertension (LIFE) study demonstrated that albuminuria is a powerful predictor for subsequent cardiovascular events, and a reduction in albuminuria during hypertension treatment can translate to a reduction in cardiovascular events [14]. These findings suggest that the reduction in albuminuria by using ARBs contributes to the suppression of cardiovascular events. Therefore, the maximal dose of candesartan also has the potential to exert a greater protective effect against cardiovascular events than lower doses, although the details remain to be elucidated.

The CASE-J trial revealed that both candesartan and amlodipine equally suppressed the incidence of cardiovascular events [9]. However, the protective effect of candesartan against cardiovascular events seemed to be strengthened "later" in the study period as compared to that of amlodipine, which exerted an effect "earlier" in the study period, suggesting that it may take some time for candesartan to exert beneficial effects. In fact, the present study also revealed that amelioration of UAE level was observed at 12 months, i.e. "later" in the observation period (Figure 1). Thereby, to exert the renoprotective effect of candesartan most effectively, it may be worth trying to prescribe the maximal dose of candesartan to hypertensive type 2 diabetic patients at least in the early stage of diabetic nephropathy.

Anti-diabetic effects of ARBs have been demonstrated in the CASE-J trial [9] and several other clinical studies 
using losartan [15], irbesartan [16] and valsartan [17], thus far. In general, angiotensin II, a potent vasoconstrictor, has the capability to impair insulin action and induce glucose intolerance $[18,19]$. Therefore, inhibition of angiotensin II action is currently believed to contribute to an improvement in insulin sensitivity or $\beta$-cell responsiveness to glucose. Although the present study failed to reveal a lowering effect on HbAlc level of the maximal dose of candesartan, the mean $\mathrm{HbAlc}$ level tended to slightly decrease between baseline and 12 months (Figure 3). It would appear that the obscure anti-diabetic effect may be attributable to the small sample size; a larger scale study would thereby help to demonstrate the beneficial effect of candesartan on glucose tolerance.

Limitations of our data include not only the small sample size and gender imbalance, but also the observational nature of the case series study; i.e. a control group continuing initial lower doses of candesartan was not set for comparison. In addition, albuminuria was characterized by determination of UAE level in a single spot-urine collection at baseline and each time point of follow-up; however, a previous study demonstrated a close correlation between spot-urine UAE level and measurements of albuminuria from overnight or 24-hour urine collection [20]. Considering the variability in determination of UAE level, only one measurement at each time point would weaken the relationship between UAE level and outcome measures. To solve this problem, a larger number sample size would be required.

It should be noted that our patients had been initially treated with lower doses ( 4 or $8 \mathrm{mg} /$ day) of candesartan without any adverse effects before the increase in dose, possibly contributing to the minimal change in serum $\mathrm{Cr}$ level and serum potassium level without any severe adverse effects in the present study. Thus, we would like to emphasize that the maximal dose of candesartan should be prescribed to diabetic patients after evaluating the tolerability of candesartan beforehand by using lower doses of candesartan.

\section{Conclusion}

In conclusion, an increase in amount of candesartan from a lower dose to the maximal dose exerted an ameliorating effect on albuminuria as well as BP in hypertensive type 2 diabetic patients in the early stage of diabetic nephropathy. Using the maximal dose of candesartan at the earliest possible time may help to prevent not only loss of renal function, but also future cardiovascular events in hypertensive type 2 diabetic patients at high cardiovascular risk.

\section{Acknowledgements}

This research received no specific grant from any fund- ing agency in the public, commercial, or not-for-profit sectors.

\section{REFERENCES}

[1] W. B. Kannel and D. L. McGee, "Diabetes and Glucose Tolerance as Risk Factors for Cardiovascular Disease: the Framingham Study," Diabetes Care, Vol. 2, No. 2, 1979, pp. 120-126. doi:10.2337/diacare.2.2.120

[2] H. C. Gerstein, J. F. Mann, Q, Yi, B. Zinman, S. F. Dinneen, B. Hoogwerf, J. P. Hallé, J. Young, A. Rashkow, C. Joyce, S. Nawaz and S. Yusuf; HOPE Study Investigators, "Albuminuria and Risk of Cardiovascular Events, Death, and Heart Failure in Diabetic and Nondiabetic Individuals," JAMA, Vol. 286, No. 4, 2001, pp. 421-426. doi:10.1001/jama.286.4.421

[3] M. Hayashi, "Development of New Therapies, Including Regeneration of the Kidney, for Chronic Kidney Diseases," Clinical and Experimental Nephrology, Vol. 10, No. 2, 2006, pp. 99-101. doi:10.1007/s10157-006-0418-7

[4] Japanese Society of Hypertension Committee, "The Japanese Society of Hypertension Guidelines for the Management of Hypertension (JSH 2009)," Hypertension Research, Vol. 32, No. 1, 2009, pp. 3-107.

[5] V. Dzau, "The Cardiovascular Continuum and Renin-Angiotensin-Aldosterone System Blockade," Journal of Hypertension-Supplement, Vol. 23, No. 1, 2005, pp. S9S17. doi:10.1097/01.hjh.0000165623.72310.dd

[6] E. J. Lewis, L. G. Hunsicker, W. R. Clarke, T. Berl, M. A. Pohl, J. B. Lewis, E. Ritz, R. C. Atkins, R. Rohde and I. Raz; Collaborative Study Group, "Renoprotective Effect of the Angiotensin-Receptor Antagonist Irbesartan in Patients with Nephropathy Due to Type 2 Diabetes," The New England Journal of Medicine, Vol. 345, No. 12, 2001, pp. 851-860. doi:10.1056/NEJMoa011303

[7] M. A. Pfeffer, K. Swedberg, C. B. Granger, P. Held, J. J. McMurray, E. L. Michelson, B. Olofsson, J. Ostergren, S and Yusuf and S. Pocock; CHARM Investigators and Committees, "Effects of Candesartan on Mortality and Morbidity in Patients with Chronic Heart Failure: the CHARM-Overall Programme," Lancet, Vol. 362, No. 9386, 2003, pp. 759-766. doi:10.1016/S0140-6736(03)14282-1

[8] H. Makino, M. Haneda, T. Babazono, T. Moriya, S. Ito, Y. Iwamoto, R. Kawamori, M. Takeuchi and S. Katayama; INNOVATION Study Group, "Prevention of Transition from Incipient to Overt Nephropathy with Telmisartan in Patients with Type 2 Diabetes," Diabetes Care, Vol. 30, No. 6, 2007, pp. 1577-1578. doi:10.2337/dc06-1998

[9] T. Ogihara, K. Nakao, T. Fukui, K. Fukiyama, K. Ueshima, K. Oba, T. Sato and T. Saruta; Candesartan Anti-hypertensive Survival Evaluation in Japan Trial Group, "Effects of Candesartan Compared with Amlodipine in Hypertensive Patients with High Cardiovascular Risks: Candesartan Antihypertensive Survival Evaluation in Japan Trial," Hypertension, Vol. 51, No. 2, 2008, pp. 393-398. doi:10.1161/HYPERTENSIONAHA.107.098475

[10] T. Saruta, K. Hayashi, T. Ogihara, K. Nakao, T. Fukui and K. Fukiyama; CASE-J Study Group, "Effects of Candesartan and Amlodipine on Cardiovascular Events in 
Hypertensive Patients with Chronic Kidney Disease: Subanalysis of the CASE-J Study," Hypertension Research, Vol. 32, No. 6, 2009, pp. 505-512. doi:/10.1038/hr.2009.44

[11] F. Locatelli, L. Del Vecchio and A. Cavalli, "Inhibition of the Renin-Angiotensin System in Chronic Kidney Disease: A Critical Look to Single and Dual Blockade," Nephron Clinical Practice, Vol. 113, No. 4, 2009, pp. c286c293. doi:10.1159/000235946

[12] K. Rossing, P. K. Christensen, B. V. Hansen, B. Carstensen and H. H. Parving, "Optimal Dose of Candesartan for Renoprotection in Type 2 Diabetic Patients with Nephropathy: A Double-Blind Randomized Cross-Over Study," Diabetes Care, Vol. 26, No. 1, 2003, pp. 150-155. doi:10.2337/diacare.26.1.150

[13] D. de Zeeuw, G. Remuzzi, H.H. Parving, W. F. Keane, Z. Zhang, S. Shahinfar, S. Snapinn, M. E. Cooper, W. E. Mitch and B. M. Brenner, "Albuminuria, a Therapeutic Target for Cardiovascular Protection in Type 2 Diabetic Patients with Nephropathy," Circulation, Vol. 110, No. 8, 2004, pp. 921-927. doi:10.1161/01.CIR.0000139860.33974.28

[14] H. Ibsen, M. H. Olsen, K. Wachtell, K. Borch-Johnsen, L. H. Lindholm, C. E. Mogensen, B. Dahlöf, R. B. Devereux, U. de Faire, F. Fyhrquist, S. Julius, S. E. Kjeldsen, O. Lederballe-Pedersen, M. S. Nieminen, P. Omvik, S. Oparil and Y. Wan, "Reduction in Albuminuria Translates to Reduction in Cardiovascular Events in Hypertensive Patients: Losartan Intervention for Endpoint Reduction in Hypertension Study," Hypertension, Vol. 45, No. 2, 2005, pp. 198-202. doi:10.1161/01.HYP.0000154082.72286.2a

[15] J. V. Lozano, J. L. Llisterri, J. Aznar and J. Redon; Spanish Working Group, "Losartan Reduces Microalbuminuria in Hypertensive Microalbuminuric Type 2 Diabetics," Nephrology Dialysis Transplantation, Vol. 16, Suppl. 1,
2001, pp. 85-89. doi:10.1093/ndt/16.suppl_1.85

[16] P. Bramlage, D. Pittrow and W. Kirch, "The Effect of Irbesartan in Reducing Cardiovascular Risk in Hypertensive Type 2 Diabetic Patients: An Observational Study in 16,600 Patients in Primary Care," Current Medical Research and Opinion, Vol. 20, No. 10, 2004, pp. 16251631. doi:10.1185/030079904X3861

[17] S. E. Kjeldsen, S. Julius, G. Mancia, G. T. McInnes, T. Hua, M. A. Weber, A. Coca, S. Ekman, X. Girerd, K. Jamerson, P. Larochelle, T. M. MacDonald, R. E. Schmieder, M. A. Schork, P. Stolt, R. Viskoper, J. Widimský and A. Zanchetti; VALUE Trial Investigators, "Effects of Valsartan Compared to Amlodipine on Preventing Type 2 Diabetes in High-Risk Hypertensive Patients: The VALUE Trial," Journal of Hypertension, Vol. 24, No. 7, 2006, pp. 1405-1412. doi:10.1097/01.hjh.0000234122.55895.5b

[18] R. H. Rao, "Pressor Doses of Angiotensin II Increase Hepatic Glucose Output and Decrease Insulin Sensitivity in Rats," Journal of Endocrinology, Vol. 148, No. 2, 1996, pp. 311-318. doi:10.1677/joe.0.1480311

[19] T. Ogihara, T. Asano, K. Ando, Y. Chiba, H. Sakoda, M. Anai, N. Shojima, H. Ono, Y. Onishi, M. Fujishiro, H. Katagiri, Y. Fukushima, M. Kikuchi, N. Noguchi, H. Aburatani, I. Komuro and Y. Fujita, "Angiotensin II-Induced Insulin Resistance Is Associated with Enhanced Insulin Signaling," Hypertension, Vol. 40, No. 6, 2002, pp. 872-879. doi:10.1161/01.HYP.0000040262.48405.A8

[20] O. Eshøj, B. Feldt-Rasmussen, M. L. Larsen and E. F. Mogensen, "Comparison of Overnight, Morning and 24Hour Urine Collections in the Assessment of Diabetic Microalbuminuria," Diabetic Medicine, Vol. 4, No. 6, 1987, pp. 531-533. doi:10.1111/j.1464-5491.1987.tb00924.x 